\title{
J.R. Leibowitz: Hidden Harmony. The Connected Worlds of Physics and Art.
}

\author{
The Johns Hopkins University Press, 2008. ISBN-13: \\ 978-0-8018-8866-3, ISBN-10: 0-8018-8866-2. 148 pages, \\ hardcover, 27 colour pictures, 22 black-and-white figures, \\ $8.9 \times 7.2 \times 0.7$ inches
}

\section{Sebastian de Haro • Thomas van Lier}

Received: 17 February 2009 / Accepted: 17 February 2009 / Published online: 24 February 2009

(C) The Author(s) 2009. This article is published with open access at Springerlink.com

\begin{abstract}
The book Hidden Harmony-The Connected Worlds of Physics and Art by J.R. Leibowitz is critically reviewed. The book is intended for a general audience and does not assume prior knowledge of physics or the arts.
\end{abstract}

Keywords Art and philosophy - Science in art · Art and science - Analytical cubism $\cdot$ Symmetry breaking $\cdot$ Form and balance $\cdot$ Conservation laws

Much has been written on, and speculated about, the connection between physics and art, the role of perception and the psychological and social factors influencing both fields. Attempts at connecting developments in physics such as Albert Einstein's formulation of the special theory of relativity and the simultaneous development of cubism by Pablo Picasso appear to be no more than suggestive proposals. Despite much research, ${ }^{1}$ it has not proved possible to firmly establish such claims of historical connections. What, if anything, is left to be said on the "physics and art" front?

J.R. Leibowitz, in Hidden Harmony-The Connected Worlds of Physics and Art, studies the role of form in physics and in the visual arts. Physics and art geniuses both apply aesthetical categories and criteria to their work. Leibowitz tries to identify the influence of those criteria in the artist's and the physicist's work. He then explains how their separate criteria are mutually connected. By displaying the developments as a creative process, he finds a number of elements that play an important role in the

\footnotetext{
${ }^{1}$ See for instance Arthur I. Miller, Einstein, Picasso: Space, Time, and the Beauty That Causes Havoc, Basic Books, 2002.

S. de Haro $(\varangle) \cdot$ T. van Lier Institute for Theoretical, Physics and Spinoza Institute, Utrecht University, Leuvenlaan 4, 3508 TD Utrecht, The Netherlands e-mail: s.deharo@uu.nl

T. van Lier

e-mail: T.J.M.vanLier@students.uu.nl
} 
birth of a physical theory as well as in what makes a piece of art "work". A few of these elements are: symmetry and its breaking; balance and rebalance; conservation; and coherence and unity. In a number of examples from physics and in a selection of paintings, he illustrates how these elements are a key to making great works.

In the first and last chapters, Leibowitz poses the problem of how physics and art are connected, and stresses the importance of form in his answer to this question. In the eight remaining chapters he analyzes, in alternating groups of two chapters, the developments in the histories of physics and art. The chapters dealing with physics will not give the working physicist any new information; they rather provide the author's own vision on a number of developments in the history of physics; as such they are a nice read.

The first two chapters on physics explain the concepts of conserved quantity, symmetry, and symmetry breaking, illustrating them with examples from nature and cosmology. Leibowitz discusses the wave- and particle-character of light in the doubleslit experiment as well as Planck's quantization condition. He stresses the relation between symmetry and information: the breaking of symmetry allows determining the properties of a particle and restores its defining information.

The next two physics chapters attempt at explaining parts of Maxwell's theory and the special theory of relativity but fall short in a number of points. Leibowitz shows the importance of charge conservation in the formulation of the Maxwell equations. Thanks to the additional term $\frac{1}{c^{2}} \frac{d E}{d t}$ on the right-hand side of the Ampère-Maxwell law, Maxwell's equations describe electric and magnetic fields as waves propagating at the speed of light. But Leibowitz fails to justify his emphasis on the way the equations look. Maxwell's equations, placed in a frame which is supposed to remind the reader of a painting, are regarded as "icons" of a composition. At this point the author gives in to a popularizing kind of prose at the expense of clarity. This chapter is apparently aimed at a public of non-scientists, but they will find it difficult to follow the explanation of the symbols.

The explanation of concepts such as time dilation and the impossibility of simultaneity contained in the chapter on special relativity will once again be opaque to the non-physicist. Nevertheless this chapter contains a few interesting points. Enlightening is his discussion of observer-independence. Leibowitz argues that relativism, in the sense of an unwarranted dependence on the existence of a special observer, lurks in the concept of the ether and hence in Maxwell's description of electromagnetism. According to Leibowitz, Einstein does away with physics relativism by introducing — or rather, restoring — observer relativity and demanding that physics be independent of the observer. Lorentz transformations thus restore the broken symmetry. In this way, the path that starts from Newton and continues via Faraday, Ampère and Maxwell, leading to Einstein, can be regarded as a process of initial symmetry, its subsequent breaking and finally its restoration: Galilean invariance is replaced by Lorentz invariance.

Four chapters on the visual arts deal with the concepts of balance and restoration of balance, coherence and unity, symmetry, and broken symmetry. Leibowitz mentions a few factors that may contribute to these. Balance, for instance, can be achieved by using form, stressing some elements more than others. He illustrates this in the sculpture of the American artist David Smith (1906-1965). By bringing one form to 
the foreground and letting it dominate another, hierarchy arises. In order not to distort the coherence with other forms, the artist uses other means, as Leibowitz explains in another painting of the nineteenth-century painter Edouard Manet.

Besides form, color also plays an important part in achieving unity and coherence. In The Old Guitarist by Pablo Picasso, for instance, the guitar is central in the composition. Since Picasso did not want to emphasize it, he gave it a rather neutral color, such that the man playing it comes to the foreground. A similar effect takes place in the The Arnolfini Wedding by Jan Van Eyck (1390-1441), where the bride's colorful dress does not misbalance the composition thanks to the strip of light in the lower left corner of the painting.

In the chapter on Impressionism a few things remain unclear. Leibowitz first mentions the way that the same colors and hues appear in different places of the painting, creating an impression of unity. Later on, the texture of brush is also seen to add to unity, but he does not explain in what way and why. Even less clear is the example of Van Gogh's Wheatfields with Cypresses (1889). Unity is in this case achieved by the distribution of related colors, but in this case the texture mainly expresses emotion.

Chapter nine, on Cézanne and Analytical Cubism, is the most clarifying one, not because the author successfully shows how certain principles from science are also present in Cubist art, but because he shows how Cézanne and his followers no longer try to imitate nature; rather, they pursue an autonomous work of art with its own (aesthetic) laws. And with that the formalist approach of art, so characteristic of Leibowitz, is born.

When he discusses the concepts such as unity, coherence and (restored) symmetry in current art, things are more complicated. Are these also applicable to performance art, installation art and video art? Leibowitz has made a choice of modern art where such principles still play a role. But that suggests that the argued connections between physics and art may not hold for all art, but mainly for the art that the author selected. The very small amount of source material and references used give the impression that his story on art is mainly based on personal interpretations lacking a serious attempt to justify them. Nevertheless it is a surprising view on art, as long as one doesn't ask too many questions.

Leibowitz offers an original perspective on the relation between physics and art and in that sense the book is worth reading. He avoids speaking of content, perception and representation, which would require a much longer book. The concentration on form allows him to identify a number of elements which contribute to the harmony of a work of art and of a physical theory. Herein lays its strength but also its weakness: the emphasis on the formal elements make the argument and the author's intentions become enigmatic at times. He does not mention how far analogies between physics and art can be pushed, or whether they point to a deeper relationship between both. On the one hand Leibowitz suggests the existence of parallels in the histories of physics and the arts; on the other hand he dismisses the suggestion of clear causal connections. Can the analogy be explained from the way great minds work, both in the natural sciences and in the arts? Does the connection between physics and the visual arts bear a special status, or can it be found between physics and other forms of artistic or media-expression as well? Or between the visual arts and other natural sciences? The lack of a theory of representation and the focus on form leaves these questions unanswered. 
Open Access This article is distributed under the terms of the Creative Commons Attribution Noncommercial License which permits any noncommercial use, distribution, and reproduction in any medium, provided the original author(s) and source are credited. 